\title{
Preparation and characterization of phosphoric acid-doped hydroxyethyl cellulose electrolyte for use in supercapacitor
}

\author{
Y. N. Sudhakar ${ }^{1}$ M. Selvakumar ${ }^{1} \cdot$ D. Krishna Bhat ${ }^{2}$
}

Received: 7 June 2014/ Accepted: 22 May 2015/Published online: 17 June 2015

(c) The Author(s) 2015. This article is published with open access at Springerlink.com

\begin{abstract}
A new borax cross-linked biodegradable solid polymer electrolyte based on hydroxyethyl cellulose and phosphoric acid $\left(\mathrm{H}_{3} \mathrm{PO}_{4}\right)$ was prepared. Characterizations of doped and undoped SPE were done using Fourier transform infrared spectroscopic and electrochemical studies. The ionic conductivity of the films increased with increase in acid concentration and the ionic conductivity obtained at $303 \mathrm{~K}$ was $4.1 \times 10^{-3} \mathrm{~S} \mathrm{~cm}^{-1}$. Furthermore, effects of acid concentration on ionic conductivity and activation energy were discussed. Dielectric studies showed long tail-like feature indicating capacitive nature. A supercapacitor was fabricated and its electrochemical characteristics were studied. The supercapacitor showed a fairly good specific capacitance of $83 \mathrm{~F} \mathrm{~g}^{-1}$ at $2 \mathrm{mV} \mathrm{s}^{-1}$ and galvanostatic charge-discharge studies showed the mirror-like pattern with $98 \%$ columbic efficiency. Cyclic stability was measured up to 2000 cycles.
\end{abstract}

Keywords Hydroxy methyl cellulose $\cdot$ Borax $\cdot \mathrm{H}_{3} \mathrm{PO}_{4}$. Supercapacitor

\section{Introduction}

Green materials have emerged has a challenging concept in research to satisfy the sustainable development and provide future generation to avail their own needs. This motivation

M. Selvakumar

chemselva@rediffmail.com

1 Department of Chemistry, Manipal Institute of Technology, Manipal University, Manipal, Karnataka, India

2 Department of Chemistry, National Institute of Technology, Surathkal, Karnataka, India among researchers has led to many engineered material in medical field and devices like battery, or supercapacitor in energy field. Only few literatures are available in which either the device as a whole or the materials in it are biodegradable [1-5]. The main materials like electrode material and electrolyte especially solid polymer electrolyte (SPE) play an important role in maintaining leak proof, better energy density, less thickness, less weight and flexible compared to its liquid counterpart [6]. Furthermore, use of liquid electrolytes needs a separator to prevent electrode-electrode contact, which drastically increases the cost. The commonly used amorphous polymers include polyacrylonitrile, polyvinylidene difluoride and polymethyl methacrylate $[7,8]$. They exhibit high conductivity due to gel formation, wherein the polymer network entraps the liquid electrolyte. Although desirable properties can be achieved using these petroleum derived polymers, they are harmful for the environment in larger quantities once discarded and they mainly depends on non-renewable sources. Despite of several efforts from the scientific community there is still lack of highly abundant and low cost SPEs which avoids use of toxic chemicals and degrades at the end of its life period. In comparison to electrolytes with alkali metal salts, proton conductors are characterized by higher dynamics of ionic transport [9].

Biologically derived and synthetic biodegradable polymers have attracted considerable attention for use as solid electrolytes in various fields [10-12]. Polymer electrolytes, such as polyethylene oxide-salt complexes, polyvinyl alcohol [13], chitosan [14], starch [15] and methyl cellulose [16] are prepared by doping of ionic salt to polymers. These are the most common SPEs employed in electrochemical devices, wherein ionic conductivity was reached up to $10^{-3} \mathrm{~S} \mathrm{~cm}^{-1}$. Pradeep et al. [2] discussed the importance and stability of the naturally derived polymer 
as an electrolyte in electrochemical device. Hydroxyethyl cellulose (HEC) is a very important cellulose derivative due to its good viscosimetric, emulsifying, stabilizing, dispersing, and agglutinant properties as well as its high solubility in several organic solvents and water and its ability to form films with desirable mechanical properties. These characteristics make HEC suitable for applications in ink, paper, food, pharmaceutical, cosmetic, ceramic, textile, and agricultural products [17] Machado et al. [18] studied HEC with different quantities of glycerol and lithium trifluoromethane sulfonate $\left(\mathrm{LiCF}_{3} \mathrm{SO}_{3}\right)$ salt, which showed ionic conductivity value of $1.07 \times 10^{-5} \mathrm{~S} \mathrm{~cm}^{-1}$ at $30{ }^{\circ} \mathrm{C}$. It is of great challenge to prepare proton conducting HEC since acid hydrolysis of intra- and inter-molecular hydrogen bonding takes place, thereby losing its filmforming properties. Moreover, HEC is crystalline in nature and addition of plasticizers, cross-linkers and different dopants certainly improves the ionic conducting and stability of polymer electrolyte. It is well known that borax (or sodium tetraborate, $\mathrm{Na}_{2} \mathrm{~B}_{4} \mathrm{O}_{7}$ ) is a good buffer and crosslinker. At lower concentrations, the borax totally dissociates into equivalent amount of boric acid and borate ion [19]. Usually borate ions and polymer molecules form complexes which induce electrostatic charges on the polymeric chains. The $\mathrm{Na}^{+}$ions will have a shielding effect on the charges of polymer chains. [20]. In addition, the hydroxyl groups of HEC form hydrogen bonding with borate ions. Thus, stabilizing the polymer matrix and creating opportunity to add acid into the HEC system. $\mathrm{H}_{3} \mathrm{PO}_{4}$ has proved to be a good proton conductor in poly(ethylenimine) [21], poly(vinyl alcohol) [22] and poly (silamine) [23] chitosan/iota-carrageenan [24]. The source of proton conduction can be obtained by self-ionization and self-dehydration of $\mathrm{H}_{3} \mathrm{PO}_{4}$ [25]. $\mathrm{H}_{3} \mathrm{PO}_{4}$ also acts as a plasticizer [26]. Addition of $\mathrm{H}_{3} \mathrm{PO}_{4}$ may further induce esterification reaction with hydroxyl groups of HEC, but acid hydrolysis of $\beta$-glucoside bonds would be minimized in presence of borax.

Supercapacitor or electrochemical double-layer capacitor (EDLC) is an electrical storage device, which can store much more energy than conventional capacitors and offer much higher power density, short charging time, long durability ( $>10^{5}$ cycles) and environment friendly features than batteries [27-30]. EDLC works on the principle of double-layer capacitance at the electrode/electrolyte interface where electric charges are accumulated on the electrode surfaces and ions of opposite charge are arranged on the electrolyte side. The use of activated carbon as electrode material increased the double-layer capacitance of the EDLC due to high surface area, porosity, stability to charge/discharge and inert to most of the electrolytes. Activated carbons derived from natural sources are attracting attention because carbon can be naturally activated due to presence of soft organics and metals in natural sources. Biswal et al. reported high surface area of $1230 \mathrm{~m}^{2} \mathrm{~g}^{-1}$ synthesized by single step pyrolysis of dead plant leaves without any activation and showed to have specific capacitance of $400 \mathrm{~F} \mathrm{~g}^{-1}$. Starch-derived activated carbon showed to have stability in EDLC. Naturally derived activated carbon in micrograms is known to have therapeutic properties [31]. A comparison of solid-state EDLC using PEO-KOH- $\mathrm{H}_{2} \mathrm{O}$ polymer electrolyte and EDLC using $\mathrm{KOH}$ aqueous electrolyte showed that the specific capacitance per gram of activated carbon is almost similar [32]. Therefore, the compatibility of the biodegradable solid polymer electrolyte with the activated carbon electrodes is an encouragement for studying ecofriendly all-solid-state EDLCs.

In this work, we demonstrate the preparation biodegradable SPE using HEC, borax as cross-linker and phosphoric acid as dopant. Ionic conductivity, dielectric constant and dielectric loss as well as the real and imaginary parts of the electrical modulus were analysed at temperature range from 303 to $343 \mathrm{~K}$. Supercapacitor was fabricated using optimized SPE and activated carbon derived from areca fibres as electrode material. Supercapacitor performance was evaluated employing AC impedance spectroscopy, cyclic voltammetry (CV) and galvanostatic charge-discharge (GCD) technique. The specific capacitance was comparable with that of supercapacitor having aqueous $\mathrm{H}_{2} \mathrm{SO}_{4}$ without the SPE. The cyclic stability during charge-discharge was studied up to 2000 cycles.

\section{Experimental section}

\section{Materials preparation}

HEC (Aldrich, average $M_{\mathrm{w}} \sim 250,000$ ) and borax (Aldrich, $99 \%$ greener alternative product) were mixed in $4: 1 \mathrm{wt} \%$ ratio and were taken in different Petri plates. $20 \mathrm{ml}$ of Millipore water was added to the mixture and stirred well to form uniform viscous solution. 0.1, 0.2, 0.4 and $0.5 \mathrm{ml}$ of $85 \%$ of $\mathrm{H}_{3} \mathrm{PO}_{4}$ was added with stirring and allowed to settle for $2 \mathrm{~h}$ and subjected to $60{ }^{\circ} \mathrm{C}$ for $2 \mathrm{~h}$. SPE films obtained were peeled out and subjected to further studies.

\section{Characterization}

Fourier transform infrared spectroscopic (FTIR) measurements of the SPEs were carried out at room temperature using Shimadzu 8400S FTIR spectrometer.

For electrochemical studies, SPE samples having thickness of $\sim 0.5$ to $0.7 \mathrm{~mm}$ measured using screw gauge were cut into $1 \mathrm{~cm} \times 1 \mathrm{~cm}$ square dimension and placed 
between two square stainless steel electrodes (length $1 \mathrm{~cm}$ ) fitted with copper wires. The whole set up was held tightly with a plastic clamp. The bulk ionic conductivities $(\sigma)$ and dielectric properties of the SPEs were determined using the $\mathrm{AC}$ impedance spectra in the frequency range of $1 \mathrm{MHz}-$ $100 \mathrm{mHz}$ using a small amplitude AC signal of $10 \mathrm{mV}$. Experiments were carried out in a closed chamber maintained at $100 \%$ relative humidity and in the range of 303-343 K using PID controlled oven from SES instruments Pvt. Ltd. From these AC impedance data, dielectric studies at different temperatures were also carried out. The formulae and relationships between complex impedance, dielectric constant and dielectric modulus can be found elsewhere [33]. Briefly, impedance is a complex number $\left(Z^{*}\right)$ and represented by its real, $Z_{\mathrm{R}}$ and imaginary, $Z_{\mathrm{I}}$ parts by the relation

$Z *=Z_{\mathrm{R}}+j Z_{\mathrm{I}}$,

where $j$ is $\sqrt{-1}$.

The equations for the dielectric constant, $\varepsilon_{\mathrm{R}}$, the dielectric loss, $\varepsilon_{\mathrm{I}}$, the real electrical modulus, $M_{\mathrm{R}}$ and the imaginary electrical modulus, $M_{\mathrm{I}}$, are represented as

$\varepsilon_{\mathrm{R}}=\frac{Z_{\mathrm{I}}}{\omega C_{\mathrm{O}}\left(Z_{\mathrm{R}}^{2}+Z_{\mathrm{I}}^{2}\right)}$

$\varepsilon_{\mathrm{I}}=\frac{Z_{\mathrm{R}}}{\omega C_{\mathrm{O}}\left(Z_{\mathrm{R}}^{2}+Z_{\mathrm{I}}^{2}\right)}$

$M_{\mathrm{R}}=\frac{\varepsilon_{\mathrm{R}}}{\left(\varepsilon_{\mathrm{R}}^{2}+\varepsilon_{\mathrm{I}}^{2}\right)}$

$M_{\mathrm{I}}=\frac{\varepsilon_{\mathrm{I}}}{\left(\varepsilon_{\mathrm{R}}^{2}+\varepsilon_{\mathrm{I}}^{2}\right)}$,

where $C_{\mathrm{O}}=\varepsilon_{\mathrm{o}} A / t$ and $\varepsilon_{\mathrm{O}}$ is the permittivity of the free space, $A$ is the electrolyte-electrode contact area and $t$ is the thickness of the sample and $\omega=2 \pi f, f$ being the frequency in $\mathrm{Hz}$.

\section{Fabrication of symmetrical supercapacitor cell}

Electrode material for supercapacitor fabrication was prepared using activated carbon (AC) derived from areca fibres [34] using polyvinylidene fluoride (PVDF) binder dissolved in $N$-methylpyrrolidone (3:1 ratio). PVDF binder solution was mixed with $\mathrm{AC}$ in $0.3: 1$ weight ratio and grinded by means of pestle and mortar to form slurry. The obtained slurry was screen printed (200 $\mu \mathrm{m}$ mesh size) on two stainless steel electrodes. The thicknesses of the coated AC layer on electrodes were around $30 \mu \mathrm{m}$ having weight of $\sim 2$ to $3 \mathrm{mg}$ each. The supercapacitor cell was constructed using SPE sandwiched between two prepared ACcoated electrodes. The unit cell was sealed in a plasticcoated aluminium pouch keeping the two wires outside. We also fabricated a cell with $2 \mathrm{~mol} \mathrm{dm}{ }^{-3} \mathrm{H}_{2} \mathrm{SO}_{4}$ solution without SPE using polypropylene sheet as separator. Electrochemical characterization was carried out by $\mathrm{CV}$, AC impedance and GCD studies. All the electrochemical studies were carried out using a BioLogic SP-150 instrument.

\section{Results and discussion}

The temperature-dependent ionic conductivity measurements were considered in order to analyze the possible mechanism of ionic conduction in these systems. The bulk ionic conductivities $(\sigma)$ of the SPEs have been determined from the complex impedance using the equation, $\sigma=L /$ $R_{\mathrm{b}} A$, where $L, R_{\mathrm{b}}$ and $A$ are the thickness, bulk resistance, and area of the SPE, respectively. The conductivity values are found in the range of $10^{-3}-10^{-4} \mathrm{~S} \mathrm{~cm}^{-1}$ for SPEs with different concentrations at different temperatures. The highest ionic conductivity value was $6.2 \times 10^{-3} \mathrm{~S} \mathrm{~cm}^{-1}$ at $343 \mathrm{~K}$ and $4.1 \times 10^{-3} \mathrm{~S} \mathrm{~cm}^{-1}$ at $303 \mathrm{~K}$. It was exhibited by sample containing (4:1) HEC:borax with $0.5 \mathrm{ml}$ of $\mathrm{H}_{3} \mathrm{PO}_{4}$. This sample was labelled as HB5 and chosen for further studies. Figure 1 show the Nyquist plots of HB5 at different temperatures, wherein semicircles are observed at high frequencies in the range of $1 \mathrm{MHz}-10 \mathrm{kHz}$ and a spike in the low frequency region. The $R_{\mathrm{b}}$ was calculated from the end of semicircle at the high-frequency intercept on to the real impedance axis of the Nyquist plot [35] as a function of temperature. The $R_{\mathrm{b}}$ values were found to be $12.4,10,9.4,8.2$ and $6.2 \Omega$ at $303,313,323,333$ and $343 \mathrm{~K}$, respectively. The $R_{\mathrm{b}}$ values decreased with increase in the temperature indicating increase in capacitance value of the electrodes at low frequencies due to a larger number of ionic and polymer segmental movements. At low frequency region, the spikes are attributed to temperature effect on the blocking electrode. The spikes are inclined with $<90^{\circ}$ to the real axis indicating the inhomogeneous

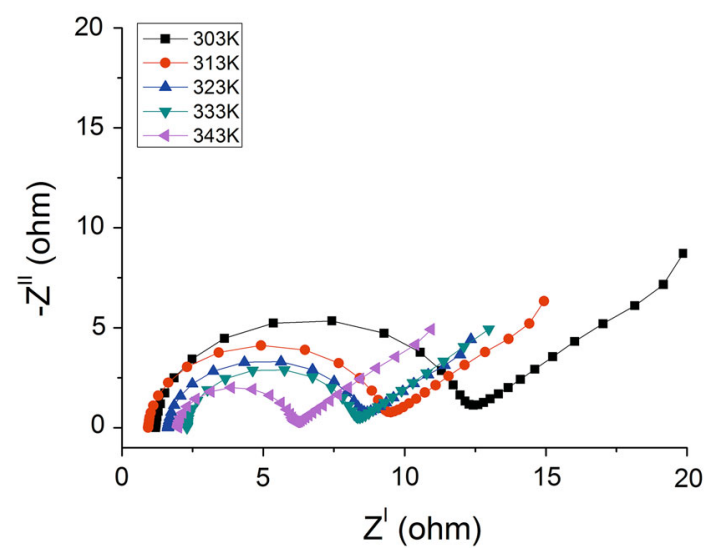

Fig. 1 Nyquist plots of the HB5 at different temperatures 
character at the electrode-electrolyte interface region. Figure 2a represents the Arrhenius plots of five different concentrations of $\mathrm{H}_{3} \mathrm{PO}_{4}$ in the HEC electrolytes with increase in temperature. Arrhenius type of behaviour is observed in all the characterized polymer electrolytes, meaning that there is neither phase transition in the polymer matrix nor domain formed by the addition of $\mathrm{H}_{3} \mathrm{PO}_{4}$. The increase in the conductivity with the temperature can be interpreted as a hopping mechanism between coordinating sites of polymers and proton. As the temperature increases, the hopping of protons usually gets assisted by local structural relaxations and segmental motions of the polymer-borax complexes [36]. The effective bonding of borax with the HEC would have helped to retain the acidic protons and hence exhibited stability while varying the temperature. Activation energy, $E_{\mathrm{A}}$, was calculated using the slope obtained by linear fitting the curves from $\log \sigma$ versus $10^{3} / T$ graph (Fig. 2b). This is based on the Arrhenius rule, $\sigma=\sigma_{0} \exp \left(-E_{\mathrm{A}} / k T\right)$, where $\sigma_{0}$ is the pre-exponential factor, $k$ is Boltzmann constant and $T$ is absolute temperature. It can be observed from Fig. 3, the values of $E_{\mathrm{A}}$ were opposite to the conductivity. The values of $E_{\mathrm{A}}$ for SPEs studied in this work are in the range of $0.092-0.12 \mathrm{eV}$. The electrolyte with lower value of $E_{\mathrm{A}}$ implies that dopant acid has been dissociated favouring proton movement by forming coordination with other polymer sites. Comparatively, the present ionic conductivity is better than other ionic conductivities exhibited by natural polymer electrolytes which ranged from $10^{-3}$ to $10^{-6} \mathrm{~S} \mathrm{~cm}^{-1}$ [37-39].

Figure 3a-c show the variation of dielectric constant $\left(\varepsilon_{\mathrm{R}}\right)$, dielectric loss $\left(\varepsilon_{\mathrm{I}}\right)$, real $\left(M_{\mathrm{R}}\right)$ and imaginary $\left(M_{\mathrm{I}}\right)$ parts of electrical modulus as a function of temperature. There are no appreciable relaxation peaks observed in the frequency range used in the study. The $\varepsilon_{R}$ (Fig. 3a) increases sharply at lower frequency region which is due to ionic charges accumulation at the electrode/electrolyte interface region. The observed behaviour at electrode/electrolyte interface region is due to ionic diffusion since accumulated protons are not able to exchange with the blocking electrodes, this is generally known as non-Debye type process [40]. On the other hand, at high frequencies, periodic reversal of the electric field occurs so fast that there is no excess ion diffusion in the direction of the field. Polarization due to charge accumulation decreases which leads to the decrease in $\varepsilon_{R}$. The effect of temperature on $\varepsilon_{R}$ shows increase in the values with increase in temperature. This indicates that there is increase in movement of ions leading to more and more dipoles orient, resulting in an increase in the dipole moment and rapid polarization at higher temperatures [4]. The $\varepsilon_{I}$ spectra (Fig. 3b) show higher values at lower frequency region than values at higher frequency region. No significant relaxation peaks have been observed in Fig. 4, since it is dominated by high concentration of mobile ions masking the relaxation peaks due to permanent or induced dipoles [41]. It is can be also suggested that at low frequencies, before there is a change in direction of field, there was no particular time taken by the charges to build up at the interfaces and thus, absence of relaxation peaks although there is very large apparent values of $\varepsilon_{I}$ [42]. As temperature increases, the values shift toward higher frequency region since the degree of acid dissociation causes the increase in the number of free ions.

In Fig. 3c, $M_{\mathrm{R}}$ values increases with increase in frequency and exhibit a long tail feature at low frequency region. This indicates that the material is very capacitive in nature [43]. A decline in the values of $M_{\mathrm{R}}$ with the increase in temperature results from an increase in the segmental motion of the polymer chains and charge carriers with the temperature. At high temperatures, the orientation of the charge carriers and molecular dipoles become easier [44]. In the Fig. 3d, the $M_{\mathrm{I}}$ exhibits lower values at lower frequency region indicating large value of capacitance associated with the electrodes. This further confirms the nonDebye type behaviour in SPEs [15]. At higher frequency region, the relaxation process was observed. The comparison of $\varepsilon_{\mathrm{I}}$ and $M_{\mathrm{I}}$ is generally used to study the localized dielectric relaxations processes from long-range conductivity. If the relaxation process is observed in $\varepsilon_{\mathrm{I}}$ and not in $M_{\mathrm{I}}$ means it is conduction process for relaxation.
Fig. 2 a Variations of bulk conductivities of SPEs with different temperatures and b variation of activation energy $\left(E_{\mathrm{A}}\right)$ and ionic conductivity $(\sigma)$ as a function of acid
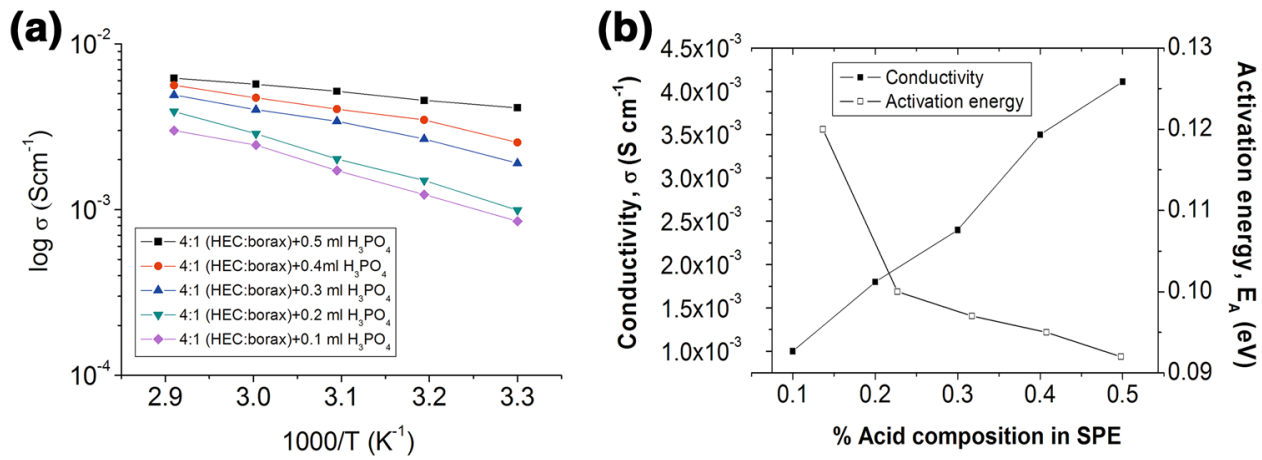

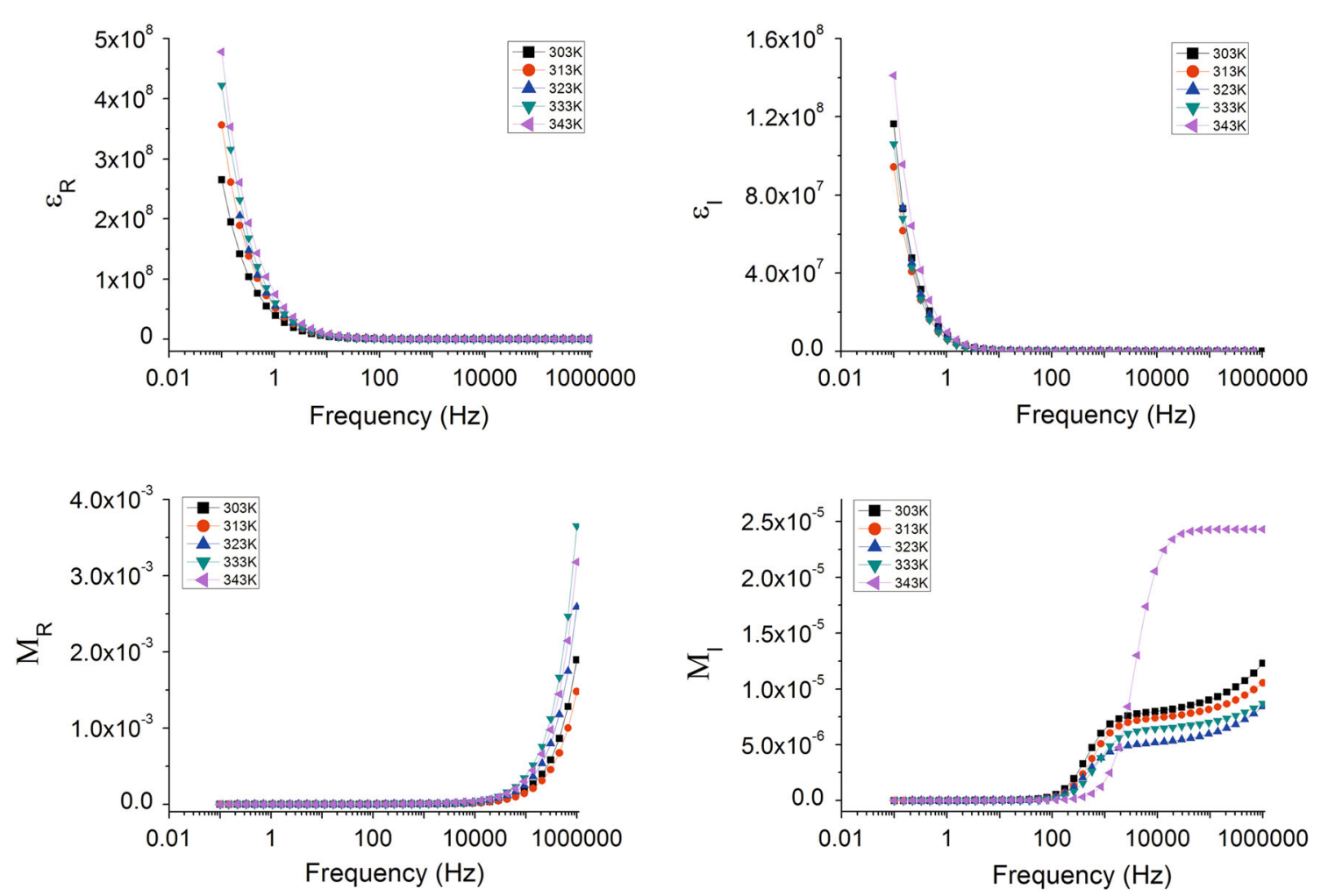

Fig. 3 Plots of dielectric studies versus frequency at different temperatures a dielectric constant, $\mathbf{b}$ dielectric loss, $\mathbf{c}$ real part of electric modulus and $\mathbf{d}$ imaginary part of electric modulus

Fig. 4 FTIR spectra of pure $\mathrm{HEC}$ and $\mathrm{H}_{3} \mathrm{PO}_{4}$ doped HEC (HB5)

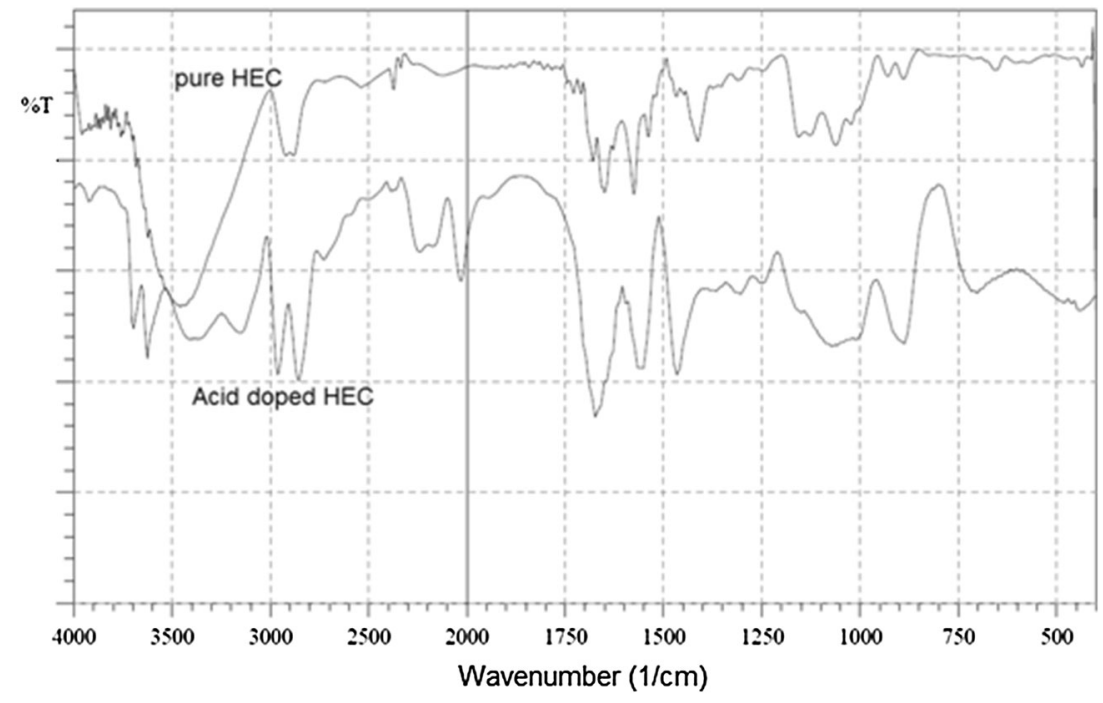

Nevertheless, for a dielectric process, a relaxation peak appears in both $\varepsilon_{\mathrm{I}}$ and $M_{\mathrm{I}}[44,45]$. In this work, the $M_{\mathrm{I}}$ exhibited relaxation peaks at higher frequency region but, no peaks were observed in $\varepsilon_{\mathrm{I}}$ which indicates that it is conduction process for relaxation. Thus, proton conductivity is Grotthuss-type wherein a proton moves rapidly from $\mathrm{H}_{3} \mathrm{O}^{+}$ to a hydrogen-bonded water molecule and it is transferred further along a series of hydrogen-bonded water molecules by rearrangement of hydrogen bonds [4]. At different temperatures, the unusual behaviour of relaxation process is observed at high-frequency region due to variation in the solution resistance wherein the relaxation are subjected to increase in chaotic thermal oscillations of unbound HEC molecules and increased disorientation of dipoles.

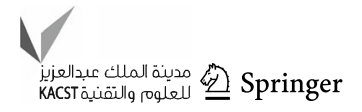


The FTIR spectrum of HEC (Fig. 4) show bands at 3487, 2923, 1658 and $1064 \mathrm{~cm}^{-1}$ characteristic for hydrogen stretching of bonded $\mathrm{O}-\mathrm{H}$, hydrogen stretching of $\mathrm{C}-\mathrm{H}$, double bond stretching of carbonyl, carboxyl and carboxyl salt and hydrogen bending of $\mathrm{O}-\mathrm{H}$, respectively. The acid-doped HEC (HB5) shows peaks at $887-1303 \mathrm{~cm}^{-1}$ which are attributed to free $\mathrm{H}_{3} \mathrm{PO}_{4}$ molecules and its anions. Peaks of carboxylate groups shifted to 1674 and $1465 \mathrm{~cm}^{-1}$ indicating enhanced interaction between borax and HEC due to addition of acid [46]. $\mathrm{H}_{2} \mathrm{PO}_{4}{ }^{-}$peak at $887 \mathrm{~cm}^{-1}$ was observed. Borax peaks were also observed at 702 and $440 \mathrm{~cm}^{-1}$ were of O-B-O group [47]. It seems that $\mathrm{H}_{3} \mathrm{PO}_{4}$ was able to break the intra/ inter molecular hydrogen bonding between $\mathrm{O}-\mathrm{H}$ groups of HEC as observed at $2854-3363 \mathrm{~cm}^{-1}$ region, but presence of borax helped to maintain the overall stability of the polymer matrix.

\section{Supercapacitor studies}

The sample with highest conductivity (HB5) was used to fabricate supercapacitor. CV responses for the carboncarbon symmetrical supercapacitor at various sweep rates are shown in Fig. 5. The specific capacitance values of the symmetrical supercapacitor device have been calculated using the equation [48];

$C=\frac{\Delta I}{\Delta V \times m}$,

where $I$ is the corresponding average current resulting from the scan rate, $\Delta V$ is the voltage scan rate, $m$ is the mass of the electrode material and $C$ is the specific capacitance. A maximum specific capacitance of $83 \mathrm{~F} \mathrm{~g} \mathrm{~g}^{-1}$ at a scan rate of $2 \mathrm{mV} \mathrm{s}^{-1}$ was obtained. The CVs with different scan rates exhibits similarity to rectangular response of electric double-layer capacitor [14]. At higher scan rates, the shape of the $\mathrm{CV}$ curves along with enclosed area deviates

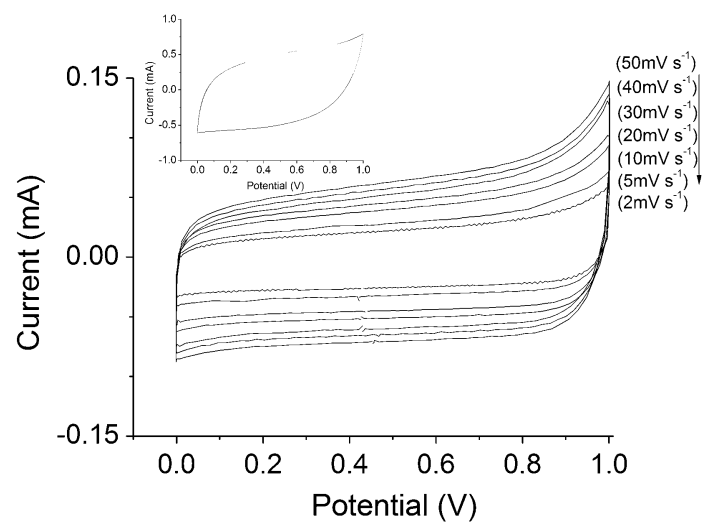

Fig. $5 \mathrm{CVs}$ of supercapacitor at different scan rates (inset $\mathrm{CV}$ of supercapacitor having aqueous $\mathrm{H}_{2} \mathrm{SO}_{4}$ ) away from rectangular shape indicating increase in diffusion resistance due to friction between the charge carriers [49-51]. As observed in Fig. 6, the values of specific capacitance decreases drastically initially with increase scan rates but higher scan rates almost similar values were obtained although increase in area under the voltammograms was observed without any major distortion of the rectangular window. This indicates that these electrodes exhibit typical capacitive behaviour with good reversibility and high stability for higher scan rates. Table 1 shows the comparison of specific capacitance of supercapacitor fabricated using similar eco-friendly SPEs and activated carbon as electrode material. The inset of Fig. 5 shows CV of supercapacitor without SPE for reference. The aqueous $\mathrm{H}_{2} \mathrm{SO}_{4}$ supercapacitor shows specific capacitance of $156 \mathrm{~F} \mathrm{~g}^{-1}$ at $2 \mathrm{mV} \mathrm{s}^{-1}$ with rectangular shape exhibiting double-layer characteristics. This suggests that the proposed SPE is stable at acid medium, but has less ionic movements for easy access of pores in activated carbon, compared to aqueous $\mathrm{H}_{2} \mathrm{SO}_{4}$ supercapacitor. The AC impedance response (Nyquist plot) of the carbon-carbon supercapacitor is shown in Fig. 7. The plot shows a semicircle at high-frequency range and a straight line in the low frequency region. The charge transfer resistance $\left(R_{\mathrm{ct}}\right)$ was obtained by subtracting highest resistance with lowest resistance at the end and beginning of the semicircle, respectively. The value of $C_{\mathrm{dl}}$, the double-layer capacitance has been determined from the high-frequency region of the impedance spectrum using the equation

$C_{\mathrm{dl}}=\frac{1}{2 \pi f_{\max } R_{\mathrm{ct}}}$,

where $f_{\max }$ is frequency at maximum imaginary axes value at semicircle region. The $C_{\mathrm{dl}}$ value obtained was $5 \mathrm{mF} \mathrm{cm}^{-2}$. The presence of large spike at low frequencies is because of an accumulation of large number of ions at

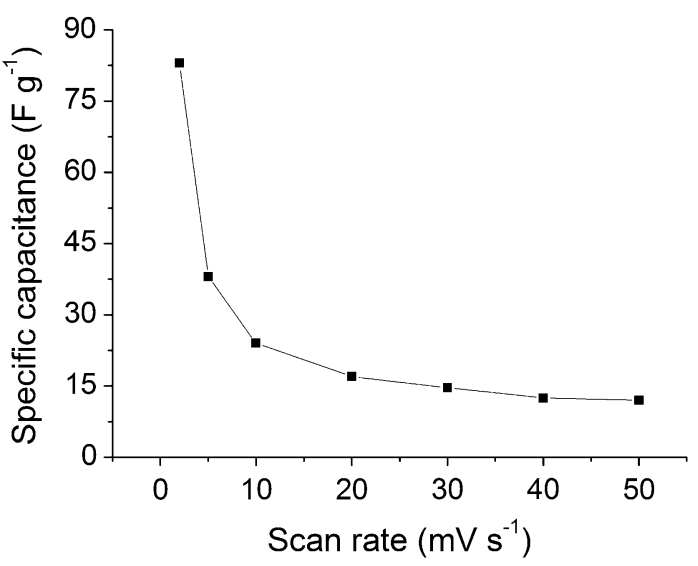

Fig. 6 Specific capacitance versus scan rates calculated from CVs 
Table 1 Comparison of specific capacitance exhibited by supercapacitors with respective scan rates

\begin{tabular}{|c|c|c|c|}
\hline Electrode material & Electrolyte & Specific capacitance & References \\
\hline $\mathrm{NiO}$ and activated carbon & $\mathrm{PVA}-\mathrm{KOH}-\mathrm{H}_{2} \mathrm{O}$ & $73 \mathrm{~F} \mathrm{~g}^{-1}$ at $10 \mathrm{mV} \mathrm{s}^{-1}$ & {$[52]$} \\
\hline Black pearl carbon & Gelatin $+\mathrm{NaCl}$ & $81 \mathrm{~F} \mathrm{~g}^{-1}$ at $5 \mathrm{mV} \mathrm{s}^{-1}$ & {$[48]$} \\
\hline Black pearl carbon & PVA-hydrogel $+2 \mathrm{M} \mathrm{HClO}_{4}$ & $91 \mathrm{~F} \mathrm{~g}^{-1}$ at $5 \mathrm{mV} \mathrm{s}^{-1}$ & {$[53]$} \\
\hline Activated carbon (BP20) & Methyl cellulose $+\mathrm{NH}_{4} \mathrm{NO}_{3}$ & $39 \mathrm{~F} \mathrm{~g}^{-1}$ at $1 \mathrm{mV} \mathrm{s}^{-1}$ & [16] \\
\hline Activated carbon & $\mathrm{HEC}+\mathrm{H}_{3} \mathrm{PO}_{4}$ & $83 \mathrm{~F} \mathrm{~g}^{-1}$ at $2 \mathrm{mV} \mathrm{s}^{-1}$ & Present wor \\
\hline
\end{tabular}

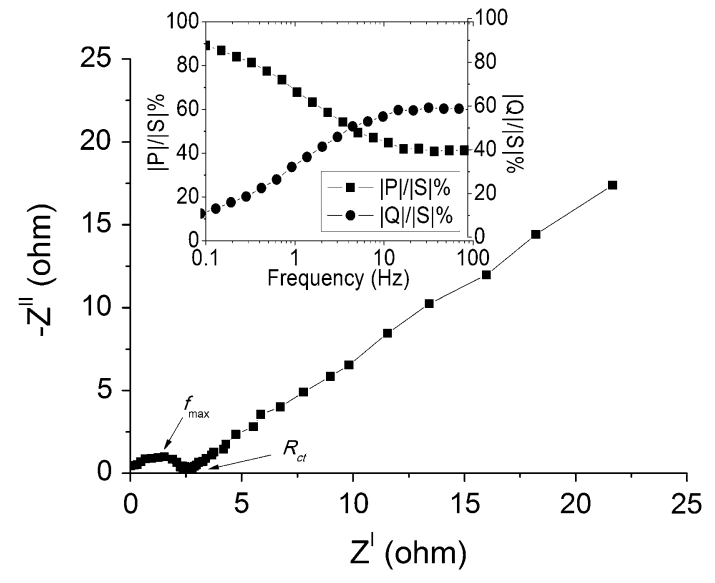

Fig. 7 AC impedance plot of supercapacitor [inset plots of normalized reactive power $|Q| /|S| \%$ and active power $|P| /|S| \%$ versus frequency $(\mathrm{Hz})]$

the electrode-electrolyte interface region, thereby supporting the double-layer property exhibited by $\mathrm{CV}$ curves. The semicircle results from the parallel combination of resistance and capacitance and the linear region is because of Warburg impedance [35].

Using normalized reactive power $|Q| /|S| \%$ and active power $|P| /|S| \%$ versus frequency plot for the $1 \mathrm{~cm}^{2}$ cell, the time constant of the fabricated supercapacitor has been calculated and is shown in Fig. 7 (inset). The theoretical details of this plotting technique have been taken from the literatures [54]. The calculated time constant was found to be equal to $0.2 \mathrm{~s}$. The time constant $\left(\tau_{0}\right)$ represents a transition for the supercapacitor between a resistive behaviour for frequency higher than $1 / \tau_{0}$ and a capacitive behaviour for frequencies lower than $1 / \tau_{0}$. Hence, the observed time constant value of $0.2 \mathrm{~s}$ indicates that the present system can be efficiently used at low frequencies.

Figure 8, represents the charge-discharge curves at different current densities namely $0.1,0.2,0.3$ and $0.4 \mathrm{~A} \mathrm{~g} \mathrm{~g}^{-1}$ at potential range of $0-1 \mathrm{~V}$. It is apparent from Fig. 8 that the charging time and also discharging pattern remained constant with increasing number of cycles, but it decreased with increase in current density. The voltage-

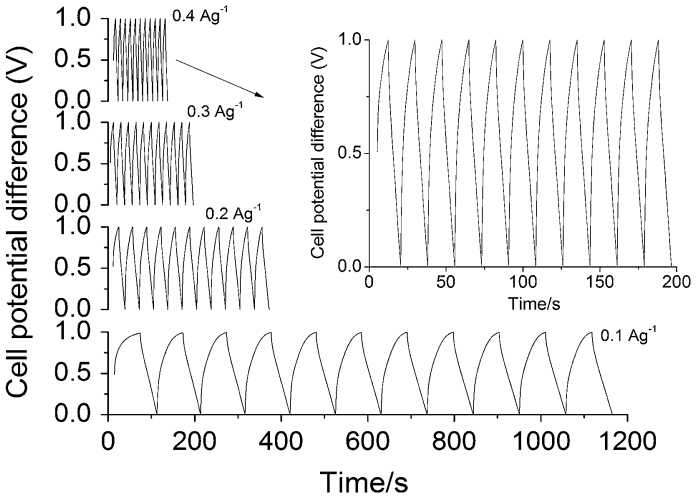

Fig. 8 Galvanostatic charge/discharge plots of supercapacitor at different current densities

time responses behaving as a mirror-like during the charge-discharge process meant that the supercapacitor owned a good electrochemical capacitance performance. The specific capacitance for the active material at room temperature was calculated [55] and found to be $110 \mathrm{~F} \mathrm{~g}^{-1}$ for the first cycle, with a coulombic efficiency of $98 \%$. Equivalent series resistance (ESR) was $24 \Omega$ for the first cycle. The ESR corresponds to sum of resistance related to ionic resistance caused in SPE, the electronic resistance of the electrode, and interface resistance between electrodes and current collectors. ESR was obtained from equation [16]

$\mathrm{ESR}=\frac{\mathrm{IR}_{\mathrm{drop}}}{2 \times I}$,

where $I R_{\text {drop }}$ is defined as the electrical potential difference between the two ends of a conducting phase during charging-discharging. Specific energy (SE) and specific power (SP) values ranged between $4 \mathrm{Wh} \mathrm{kg}^{-1}$ and $830 \mathrm{~W} \mathrm{~kg}^{-1}$. Figure 9 shows cyclic stability during charge-discharge studied up to 2000 cycles at $0.2 \mathrm{~A} \mathrm{~g}^{-1}$. The stability of supercapacitor material was quite good as seen in the capacitance values in the plot. The initial decrease in the capacitance values is minimum, which is due to the loss of the charges initially stored at interfaces 


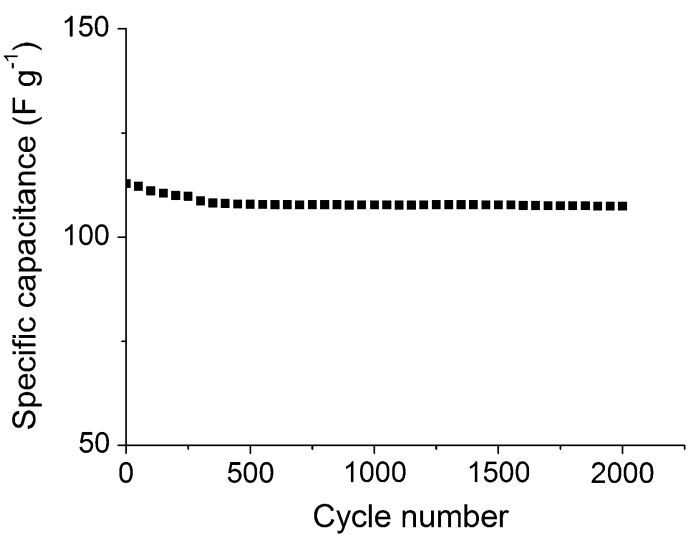

Fig. 9 Specific capacitance versus number of cycles calculated from GCD data

associated with the irreversible reactions of loosely bound surface groups on the porous activated carbon electrodes.

\section{Conclusion}

In summary, we have reported studies on supercapacitor based on activated carbon electrode and HEC solid polymer electrolyte. The addition of borax proved to have stabilized the bonding within the polymer chains when doped with $\mathrm{H}_{3} \mathrm{PO}_{4}$. The maximum conductivity was found to be $4.1 \times 10^{-3} \mathrm{~S} \mathrm{~cm}^{-1}$ at $303 \mathrm{~K}$. Better dissociation property of SPE system was evident from the activation energy of $0.12 \mathrm{eV}$ at $303 \mathrm{~K}$. The dielectric studies indicated the high capacitive nature and supported the structure of SPE. A fabricated carbon-carbon supercapacitor showed specific capacitance of $83 \mathrm{~F} \mathrm{~g}^{-1}$ at $2 \mathrm{mV} \mathrm{s}^{-1}$. This value was two times less when compared to supercapacitor fabricated using aqueous $\mathrm{H}_{2} \mathrm{SO}_{4}$. The supercapacitor showed good specific power and specific energy and was quite stable during charge-discharge cycles maintaining $98 \%$ coulombic efficiency.

Acknowledgments The authors acknowledge with thanks the financial support received from the Defence and Research Development Organization (DRDO), Govt. of India, New Delhi.

Open Access This article is distributed under the terms of the Creative Commons Attribution 4.0 International License (http://creativecommons.org/licenses/by/4.0/), which permits unrestricted use, distribution, and reproduction in any medium, provided you give appropriate credit to the original author(s) and the source, provide a link to the Creative Commons license, and indicate if changes were made.

\section{References}

1. Irimia-Vladu, M.: "Green" electronics: biodegradable and biocompatible materials and devices for sustainable future. Chem. Soc. Rev. 43, 588 (2014)
2. Varshney, P., Gupta, S.: Natural polymer-based electrolytes for electrochemical devices: a review. Ionics (Kiel) 17, 479-483 (2011)

3. Xiao, S., Wang, F., Yang, Y., Chang, Z., Wu, Y.: An environmentally friendly and economic membrane based on cellulose as a gel polymer electrolyte for lithium ion batteries. RSC Adv. 4, 76 (2014)

4. Sudhakar, Y.N., Selvakumar, M.: Ionic conductivity studies and dielectric studies of poly(styrene sulphonic acid)/starch blend polymer electrolyte containing $\mathrm{LiClO}_{4}$. J. Appl. Electrochem. 43, 21-29 (2012)

5. Yin, L., Huang, X., Xu, H., Zhang, Y., Lam, J., Cheng, J., Rogers, J.: Materials, designs, and operational characteristics for fully biodegradable primary batteries. Adv. Mater. (2014). doi:10. 1002/adma.201306304

6. Murata, K., Izuchi, S., Yoshihisa, Y.: An overview of the research and development of solid polymer electrolyte batteries. Electrochim. Acta 45, 1501-1508 (2000)

7. Baskakova, Y.V., Yarmolenko, O.V., Efimov, O.N.: Polymer gel electrolytes for lithium batteries. Russ. Chem. Rev. 81, 367-380 (2012)

8. Senthilkumar, S.T., Selvan, R.K., Ponpandian, N., Melo, J.S.: Redox additive aqueous polymer gel electrolyte for an electric double layer capacitor. RSC Adv. 2, 8937 (2012)

9. Dilip, K., Pradhan, R.N.P., Choudhary, K., Samantaray, B.K.: Studies of dielectric relaxation and AC conductivity behavior of plasticized polymer nanocomposite electrolytes. J. Electrochem. Sci. 3, 597-604 (2008)

10. Oudenhoven, J.F.M., Baggetto, L., Notten, P.H.L.: All-solid-state lithium-ion microbatteries: a review of various three-dimensional concepts. Adv. Energy Mater. 1, 10-33 (2011)

11. Agrawal, R.C., Pandey, G.P.: Solid polymer electrolytes: materials designing and all-solid-state battery applications: an overview. J. Phys. D Appl. Phys. 41, 223001 (2008)

12. Chandrasekhar, V.: Polymer solid electrolytes: synthesis and structure. Adv. Polym. Sci. 135, 139 (2008)

13. Yang, C.C., Wu, G.M.: Study of microporous PVA/PVC composite polymer membrane and it application to $\mathrm{MnO}_{2}$ capacitors. Mater. Chem. Phys. 114, 948-955 (2009)

14. Kumar, M.S., Bhat, D.K.: $\mathrm{LiClO}_{4}$-doped plasticized chitosan as biodegradable polymer gel electrolyte for supercapacitors. J. Appl. Polym. Sci. 114, 2445-2454 (2009)

15. Khiar, A.S.A., Arof, A.K.: Conductivity studies of starch-based polymer electrolytes. Ionics (Kiel) 16, 123-129 (2009)

16. Shuhaimi, N.E.A., Teo, L.P., Woo, H.J., Majid, S.R., Arof, A.K.: Electrical double-layer capacitors with plasticized polymer electrolyte based on methyl cellulose. Polym. Bull. 69, 807-826 (2012)

17. Machado, G., Prud'homme, R., Pawlicka, A.: Conductivity and thermal analysis studies of solid polymeric electrolytes based on plasticized hydroxyethyl cellulose. E-Polymers 4-12 (2007)

18. Machado, G.O., Ferreira, H.C., Pawlicka.: Influence of plasticizer contents on the properties of HEC-based solid polymeric electrolytes. Electrochim. Acta 50, 3827-3831 (2005)

19. Pezron, E., Ricard, A., Lafuma, T., Audebert, R.: Reversible gel formation induced by ion complexation. 1. Borax-galactomannan interactions. Macromolecules 21, 1121 (1988)

20. Pezron, E., Leibler, L., Ricard, A., Lafuma, T., Audebert, R.: Reversible gel formation induced by ion complexation. 2. Phase diagrams. Macromolecules 21, 1126 (1988)

21. Tanaka, R., Yamamoto, H., Kawamura, S., Iwase, T.: Proton Conducting behavior of poly (etheylenimine) $-\mathrm{H}_{3} \mathrm{PO}_{4}$ system. Electrochim. Acta 40, 2421 (1995)

22. Gupta, P.N., Singh, K.P.: Characterization of $\mathrm{H}_{3} \mathrm{PO}_{4}$ based PVA complex system. Solid State Ion. 86, 319-323 (1996) 
23. Tsuruhara, K., Rikukawa, M., Sanui, K., Ogata, N., Nagasaki, Y., Kato, M.: Synthesis of proton conducting polymer based on poly(silamine). Electrochim. Acta 45, 1391 (2000)

24. Arof, A.K., Shuhaimi, N.E.A., Alias, N.A.A., Kufian, M.Z., Majid, S.R.: Application of chitosan/iota-carrageenan polymer electrolytes in electrical double layer capacitor (EDLC). J. Solid State Electrochem. 14, 2145-2152 (2010)

25. He, R., Li, Q., Xiao, G., Bjerrum, N.J.: Proton conductivity of phosphoric acid doped polybenzimidazole and its composites with inorganic proton conductors. J. Membr. Sci. 226, 169-184 (2003)

26. Kufian, M.Z., Majid, S.R., Arof, A.K.: Dielectric and conduction mechanism studies of PVA-orthophosphoric acid polymer electrolyte. Ionics 13, 231-234 (2007)

27. Vieira, D.F., Avellaneda, C.O., Pawlicka, A.: Conductivity study of a gelatin-based polymer electrolyte. Electrochim. Acta 53, 1404-1408 (2007)

28. Stephan, A.M.: Review on gel polymer electrolytes for lithium batteries. Eur. Polym. J. 42, 21 (2006)

29. Burke, A.: Ultracapacitors: why, how, and where is the technology. J. Power Sources 91, 37-50 (2000)

30. Winter, M., Brodd, R.J.: What are batteries, fuel cells, and supercapacitors. Chem. Rev. 10, 4245 (2004)

31. Brigger, I., Dubernet, C., Couvreur, P.: Nanoparticles in cancer therapy and diagnosis. Adv. Drug Deliv. Rev. 54, 631-651 (2002)

32. Lewandowski, A., Zajdeer, M., Frackowiak, E., Beguin, F.: Supercapacitor based on activated carbon and polyethylene oxide- $\mathrm{KOH}-\mathrm{H}_{2} \mathrm{O}$ polymer electrolyte. Electrochim. Acta 46, 2777 (2001)

33. Sudhakar, Y.N., Selvakumar, M.: Lithium perchlorate doped plasticized chitosan and starch blend as biodegradable polymer electrolyte for supercapacitors. Electrochim. Acta 78, 398-405 (2012)

34. Natalia, M.: Activated carbon derived from natural sources and electrochemical capacitance of double layer capacitor. Indian J. Chem. Tech. 20, 392-399 (2013)

35. Chowdhury, N.A., Shukla, A.K., Sampath, S., Pitchumani, S.: Cross-linked polymer hydrogel electrolytes for electrochemical capacitors. J. Electrochem. Soc. 153, A614 (2006)

36. Raphael, E., Avellaneda, C.O., Manzolli, B., Pawlicka, A.: Agarbased films for application as polymer electrolytes. Electrochim. Acta 55, 1455-1459 (2010)

37. Pawlicka, A., Danczuk, M., Wieczorek, W., Zygadlo-Monikowska, E.: Influence of plasticizer type on the properties of polymer electrolytes based on chitosan. J. Phys. Chem. A 112, 8888 (2008)

38. Mohamed, S., Johari, N., Ali, A.: Electrochemical studies on epoxidised natural rubber-based gel polymer electrolytes for lithium-air cells. J. Power Sources 183, 351-354 (2008)

39. Ali, A.M.M., Subban, R.H.Y., Bahron, H., Winie, T., Latif, F., Yahya, M.Z.A.: Grafted natural rubber-based polymer electrolytes: aTR-FTIR and conductivity studies. Ionics 14, 491-500 (2008)

40. Shafee, E.E.: Dielectric and conductivity relaxation in sodium carboxymethyl cellulose and its acid form. Carbohydr. Polym. 31, 93-98 (1996)
41. Jayathilaka, P.A.R.D., Dissanayake, M.A.K.L., Albinsson, I., Mellander, B.: Dielectric relaxation, ionic conductivity and thermal studies of the gel polymer electrolyte system PAN/EC/ PC/LiTFSI. Solid State Ion. 156, 179-195 (2003)

42. Bozkurt, A.: Dielectric and conductivity relaxations in quaternary ammonium polymer. J. Phys. Chem. Solids 63, 685 (2002)

43. Qian, X., Gu, N., Cheng, Z., Yang, X., Wang, E., Dong, S.: Impedance study of $(\mathrm{PEO})_{10} \mathrm{LiClO}_{4}-\mathrm{Al}_{2} \mathrm{O}_{3}$ composite polymer electrolyte with blocking electrodes. Electrochim. Acta 46, 1829 (2001)

44. Bhatt, A.S., Bhat, D.K., Santosh, M.S.: Electrochemical properties of chitosan- $\mathrm{Co}_{3} \mathrm{O}_{4}$ nanocomposite films. J. Electroanal. Chem. 657, 135-143 (2011)

45. Hodge, I.M., Ingram, M.D., West, A.R.: Impedance and modulus spectroscopy of polycrystalline solid electrolytes. J. Electroanal. Chem. 74, 125 (1976)

46. MacFarlane, D.R., Sun, J., Meakin, P., Fasoulopoulos, P., Hey, J., Forsyth, M.: Structure-property relationships in plasticized solid polymer electrolytes. Electrochim. Acta 40, 2131 (1995)

47. Arof, A.K., Majid, S.R.: FTIR studies of chitosan-orthophosphoric acid-ammonium nitrate-aluminosilicate polymer. Mol. Cryst. Liq. Cryst. 484, 107 (2008)

48. Choudhury, A.N., Sampath, S., Shukla, A.K.: Gelatin hydrogel electrolytes and their application to electrochemical supercapacitors. J. Electrochem. Soc. 155, A74 (2008)

49. Lei, C., Wilson, P., Lekakou, C.: Effect of poly(3,4-ethylenedioxythiophene) (PEDOT) in carbon-based composite electrodes for electrochemical supercapacitors. J. Power Sources 196, 7823-7827 (2011)

50. Judeninstein, T., Reichert, P., deAzevedo, D., Bonagambac, E.R.: NMR multi-scale description of ionic conductivity mechanisms. Acta Chim. Slov. 52, 349 (2005)

51. Farma, R., Deraman, M., Awitdrus, A., Talib, I.A., Taer, E., Basri, N.H., Manjunatha, J.G., Ishak, M.M., Dollah, B.N.M., Hashmi, S.A.: Preparation of highly porous binderless activated carbon electrodes from fibres of oil palm empty fruit bunches for application in supercapacitors. Bioresour. Technol. 132, 254-261 (2013)

52. Yuan, C., Zhang, X., Wu, Q., Gao, B.: Effect of temperature on the hybrid supercapacitor based on $\mathrm{NiO}$ and activated carbon with alkaline polymer gel electrolyte. Solid State Ion. 177, 1237-1242 (2006)

53. Sampath, S., Choudhury, N.A., Shukla, A.K.: Hydrogel membrane electrolyte for electrochemical capacitors. J. Chem. Sci. 121, 727-734 (2009)

54. Taberna, P.L., Simon, P., Fauvarque, J.F.: Electrochemical characteristics and impedance spectroscopy studies of carboncarbon supercapacitors. J. Electrochem. Soc. 150, A292 (2003)

55. Hastak, R.S., Sivaraman, P., Potphode, D.D., Shashidhara, K., Samui, A.B.: All solid supercapacitor based on activated carbon and poly [2,5-benzimidazole] for high temperature application. Electrochim. Acta 59, 296-303 (2012) 